\title{
PENGARUH LATIHAN PLYOMETRIC (PULLOVER TOSS) TERHADAP HASIL (THROW IN) DALAM PERMAINAN SEPAK BOLA
}

\author{
Muhammad Erfan ${ }^{1}$ \\ Email: erfanjulianto92@gmail.com ${ }^{1}$ \\ ${ }^{1}$ Program Studi Pendidikan Olahraga Pascasarjana Universitas Negeri Malang
}

\begin{abstract}
Abstrak
Salah satu cabang olahraga yang paling terkenal di dunia adalah permainan sepak bola hal ini tidak dapat dipungkiri di Indonesia oleh ini sangat banyak peminatnya. Lemparan kedalam merupakan salah satu tehnik yang harus dikuasai dengan baik oleh seorang pemain sepak bola. Penelitian ini bertujuan untuk mengetahui "Pengaruh Latihan Plyometrik (Pullover Toss) Terhadap Hasil Lempara Kedalam (throw in) Dalam Permainan Sepak Bola Pada Klub Pelor Mas Sekotong'. Metode yang digunakan pada penelitian ini adalah menggunakan Metode Eksperimen dengan desain penelitian One Group Pretest-Posttes Design. Penentuan sampel menggunakan tehnik sampling jenuh (studi populasi) jumlah sampel sebanyak 17 orang. sedangkan analisis data menggunakan analisis data statistik dengan rumusan t-test. Berdasarkan pada analisa data untuk menjawab hipotesis penelitian yang diajukan, diperoleh nilai " $t$ " hitung sebesar 4,608 maka berdasarkan taraf signifikan 5\% dan df N-1 (17-1) = 16, ternyata batas penolakan hipotesisnya nol yang dinyatakan dalam tabel adalah 2,120 sehingga disimpulkan bahwa ada pengaruh latihan plyometrik (pullover toss) terhadap hasil lemparan kedalam (throw in) dalam permainan sepak bola pada klub Pelor Mas sekotong.
\end{abstract}

Kata Kunci : Latihan Pullover Toss, (Throw In)

\begin{abstract}
One of the most famous sports in the world is the game of football this is undeniable in Indonesia by this very many fans. Throwing in is one of the techniques that must be mastered well by a footballer. This study aims to find out 'The Influence of Plyometric Exercises (Pullover Toss) on Throw in Football at Pelor Mas Sekotong Club". The method used in this research is to use Experimental Method with One Group Pretest-Posttes Design research design. Determination of samples using saturated sampling techniques (population studies) the number of samples as many as 17 people. while data analysis using statistical data analysis with t-test formulation. Based on data analysis to answer the proposed research hypothesis, obtained a calculated value of " $t$ " of 4,608 then based on a significant level of 5\% and $d f N-1(17-1)=16$, it turns out that the limit of rejection of the hypothesis is zero stated in the table is 2,120 so it is concluded that there is an influence of plyometric exercises (pullover toss) on the result of throwing in football at Pelor Mas sekotong club.
\end{abstract}

Keywords: Pullover Toss Exercises, (Throw In) 


\section{A. Pendahuluan}

Cabang olahraga sepak bola merupakan salah satu cabang olahraga yang dianggap sukses dari segi pemasalahan. Sehingga cabang olahraga sepak bola paling populer di masyarakat, cabang olahraga ini digemari oleh seluruh lapisan masyarakat dari anak-anak hingga orang tua. Dibuktikan dengan semakin banyaknya bermunculan klub-klub olahraga. Hal ini membuktikan banyaknya orang-orang yang menyukai olahraga sepak bola. Dewasa ini sepak bola tidak hanya sebagai olahraga biasa, tetapi sudah menjadi olahraga profesional, dimana banyak orang yang menggantungkan dirinya dari bermain sepak bola dan tidak sedikit orang yang menjadi milyader dari sepak bola. Disamping itu cabang olahraga sepak bola sudah menjadi kegiatan intertaiment dan industri. Terutama dinegara-negara maju sepak bola merupakan cabang olahraga yang menghasilkan devisa baik bagi pelakunya maupun negara. Sedangkan dinegara-negara berkembang sepak bola sebagai tontonan yang sangat menarik. Seperti halnya di Indonesia pencinta sepak bola semakin lama semakin mengesankan peminatnya. Menurut (Yulifri,2011:107) Permainan sepak bola banyak menggunakan strategi dan teknik yang harus terus dikembangkan untuk menciptakan sebuah permainan yang menarik serta menciptakan kemenangan dalam sebuah tim, untuk mendukung itu semua teknik-teknik dasar sepak bola harus dikuasai dengan baik, di dalam permainan sepak bola banyak sekali teknik dasar yang harus dipelajari atau dilatih. Teknik sepak bola dengan menggunakan bola antara lain: teknik menendang bola, teknik menahan bola, teknik menggiring bola, teknik gerak tipu, teknik menyundul bola, teknik lemparan ke dalam, teknik penjaga gawang (Kemendikbud,2013:2) Menurut Bisanz (1982) dalam Yulifri (2011:78-79), Teknik dasar sepak bola dibagi menjadi dua teknik dengan tanpa bola dan teknik menggunakan bola.

Bermain sepak bola memerlukan kemampuan dasar yang baik yang akan membentuk kerjasama tim dan memajukan kualitas dalam bermain hingga menghasilkan kemenangan. Untuk meningkatkan kemampuan dasar tersebut, dapat dilakukan dengan berlatih gerakan dasar sederhana dengan aturan yang disesuaikan. Pengajaran materi sepak bola dapat menggunakan atau memanfaatkan teknik-teknik dasar. Mielke (2007) memaparkan bahwa ada tujuh teknik dasar yang perlu disanggupi oleh seorang pemain, seperti; trapping (mengandaikan), shooting (menyepak), passing (mengumpan), heading (menyundul), dribbling (menggiring), juggling (menimang), serta throw-in (lemparan ke dalam). Throw-in bermanfaat melakukan umpan jarak dekat atau jarak jauh sesuai dengan sasaran yang diinginkan, dalam penelitian ini nantinya diusahakan agar hasil throw-in baik ( dengan jarak jauh ), karena throw-in dengan jarak yang jauh dapat dimanfaatkan sebagai umpan lambung kedepan gawang lawan sebagai awal dari suatu penyerangan. Throw-in yang semakin jauh akan semakin baik dan menguntungkan suatu tim. Disamping tehnik, kemampuan fisik juga harus mendapatkan perhatian secara khusus, karena kedua hal tersebut menentukan dalam menciptakan gol dalam permainan sepak bola. Berdasarkan uraian di atas, maka dapat ditarik suatu rumusan masalah sebagai berikut: "Apakah ada pengaruh latihan plyometrik (pullover toss) terhadap hasil (throw in) dalam permainan sepak bola. Penelitian ini bertujuan untuk mengetahui "Pengaruh Latihan Plyometrik (Pullover Toss) Terhadap Hasil Lemparan Kedalam (throw in) Dalam Permainan Sepak Rnla Pada Klub Pelor Mas Sekotong '. Agar tidak terjadi kekeliruan dalam menafsirkan i: h-istilah yang ada dalam penelitian yang berbunyi: Pengaruh Latihan Plyometrik ( $\mathrm{Pl}$ ver Toss) Terhadap terhadap hasil (throw in) dalam permainan sepak bola, maka perlu dijelaskan beberapa istilah yang di anggap penting yaitu sebagai berikut:

o Pengaruh

Pengaruh adalah daya yang ada atau timbul dari suatu (orang, benda) yang ikut membentuk watak perbuatan, kepercayaan atau perbuatan seseorang.

○ Latihan Pullover Toss 
Latihan pullover toss adalah bentuk latihan memantulkan bola di atas kepala. Bentuk latihan ini merupakan latihan untuk meningkatkan kekuatan dan tenaga badan bagian atas.

- Lemparan Kedalam

Lemparan kedalam adalah suatu cara untuk memulai kembali permainan. Lemparan kedalam diberikan kepada lawan dari pemain yang terakhir menyentuh bola ketika seluruh bagian bola melewati garis samping, baik menggelinding di tanah maupun melayang di udara (Tim PSSI, 2010:72).

o Permainan Sepak Bola

Permainan sepak bola merupakan permainan yang dilakukan oleh dua regu/tim. Setiap tim terdiri atas 11 pemain. Permainan sepak bola membutuhkan kerja sama tim yang kompak (Chandra, 2010:2).

Dalam buku penelitian dijelaskan bahwa : "Hipotesis merupakan jawaban sementara terhadap rumusan masalah penelitian, di mana rumusan masalah telah dinyatakan dalam bentuk kalimat pertanyaan" (Sugiyono 2010:96). Sedangkan pendapat lain menyatakan bahwa: "hipotesis dapat diartikan sebagai suatu jawaban yang bersifat sementara terhadap permasalahan penelitian sampai terbukti melaluii data yang terkumpul. (Arikunto, 2010:110). hipotesis yang diajukan adalah sebagai berikut hipotesis alternatif yang disingkat dengan Ha, yang berbunyi sebagai berikut: "Ada pengaruh latihan plyometrik (pullover toss) terhadap hasil (throw in) dalam permainan sepak bola.

\section{B. Metode}

Rancangan penelitian dapat diartikan sebagai strategi yang mengatur tentang tujuan penelitian, yang pada dasarnya merupakan keseluruhan proses pemikiran dan penentuan matang tentang hal-hal yang di teliti. Ditinjau dari pengambilan data, bentuk bentuk data yang akan di dapat serta tujuan, maka jenis penelitian tergolong dalam penelitian eksperimental desain penelitian One GroupPretest-Posttes Design. Dengan demikian maka dalam penelitian ini sesuai dengan tujuan serta sifat masalahnya yaitu penelitian eksperimental sungguhan. Setiap orang akan mengadakan penelitian pasti berhadapan dengan populasi. Seorang ahli mengatakan bahwa populasi adalah wilayah generalisasi yang terdiri atas obyek/subyek yang mempunyai kalitas dan karekteristik tertentu yang ditetapkan oleh peneliti untuk dipelajari dan kemudian ditarik kesimpulannya (Sugiyono 2010:117). Sedangkan ahli lain mengatakan bahwa populasi adalah "keseluruhan subyek penelitian" (Arikunto, 2010:173). Dari kedua pendapat tersebut dapat disimpulkan bahwa yang dimaksut dengan populasi dalam hal ini adalah seluruh pemain sepak bola klub Pelor Mas Sekotong Tengah yang berjumlah 17 orang. Untuk itu dalam penelitian ini peneliti mempergunakan (Studi populasi) karena yang diambil sebagai subyek penelitian adalah seluruh anggota klub sepak bola Pelor Mas Sekotong yang berjumlah 17 orang. untuk memperoleh data dalam penelitian menggunakan metode tes perbuatan sebagai metode pokok sedangkan metode dokumentasi sebagai metode bantu sedangkan analisis data menggunakan analisis data statistik dengan rumusan $t$-test.

$$
t=\frac{M d}{\sqrt{\frac{\sum x^{2} d}{N(N-1)}}}
$$

Keterangan:

Md : mean dari deviasi (d) antara post-test dan pre-test

$\mathrm{xd}$ : perbedaan deviasi dengan mean deviasi 
$\mathrm{N}$ : banyaknya subyek

df : atau db adalah N-1

\section{Hasil dan Pembahasan}

(Suharsimi, 2010:125)

Tabel 1. Data tentang hasil pengukuran prestasi lemparan kedalam Sebelum melakukan latihan pullover toss (pre test)

\begin{tabular}{cccccc}
\multirow{2}{*}{ No } & Nama & \multicolumn{4}{c}{ Hasil lemparan kedalam (meter) } \\
\cline { 3 - 6 }$(1)$ & $(2)$ & I & II & III & Terbaik \\
\hline 1 & AA & 8.25 & 8.3 & 8.2 & 8.3 \\
2 & BR & 8.45 & 8.5 & 8,3 & 8.5 \\
3 & FIR & 8.3 & 8.37 & 8.4 & 8.4 \\
4 & MR & 8.5 & 8.43 & 8.11 & 8.5 \\
5 & MDN & 8.1 & 8.15 & 8 & 8.15 \\
6 & MKM & 8.2 & 8.5 & 8.4 & 8.5 \\
7 & OE & 8.4 & 8.1 & 8.13 & 8.4 \\
8 & HRN & 8.7 & 8.45 & 8.4 & 8.7 \\
9 & SDI & 8.5 & 8.7 & 8 & 8.7 \\
10 & HRI & 8.5 & 8.1 & 7.9 & 8.5 \\
11 & LE & 8.5 & 8.2 & 8.3 & 8.5 \\
12 & DD & 8.2 & 8.6 & 8.42 & 8.6 \\
13 & MK & 8.15 & 8.13 & 8.10 & 8.15 \\
14 & AHY & 8.25 & 8.15 & 8 & 8.25 \\
15 & RMI & 8 & 8.17 & 8.13 & 8.17 \\
16 & HKO & 8.11 & 8.10 & 8 & 8.11 \\
17 & AGS & 8 & 8.17 & 8.14 & 8.17 \\
\hline & & & & &
\end{tabular}

Tabel 2. Data tentang hasil pengukuran prestasi lemparan kedalam setelah melakukan latihan pullover toss (post test)

\begin{tabular}{cccccc} 
No & Nama & \multicolumn{4}{c}{ Hasil lemparan kedalam (meter) } \\
\cline { 3 - 6 } & & I & II & III & Terbaik \\
$(1)$ & $(2)$ & $(3)$ & $(4)$ & $(5)$ & $(6)$ \\
1 & AA & 8.5 & 8.9 & 8.6 & 8.9 \\
2 & BR & 8.7 & 8.6 & 9 & 9 \\
3 & FIR & 8.8 & 8.5 & 8.3 & 8.8 \\
\hline
\end{tabular}




\begin{tabular}{cccccc}
\hline 4 & MR & 8.7 & 8.4 & 8.5 & 8.7 \\
5 & MDN & 8.3 & 8 & 8.2 & 8.3 \\
6 & MKM & 8.10 & 8.17 & 8.6 & 8.6 \\
7 & OE & $8 . .8$ & 8.3 & 8.6 & 8.8 \\
8 & HRN & 9 & 8.8 & 8.6 & 9 \\
9 & SDI & 8.56 & 8.85 & 8.65 & 8.85 \\
10 & HRI & 8.7 & 8.15 & 7.9 & 8.7 \\
11 & LE & 8.73 & 8.53 & 8.12 & 8.73 \\
12 & DD & 8.67 & 8.12 & 8.32 & 8.67 \\
13 & MK & 8.27 & 8.10 & 8.13 & 8.27 \\
14 & AHY & 8.32 & 8.12 & 8.9 & 8.32 \\
15 & RMI & 8.26 & 8.9 & 8.11 & 8.26 \\
16 & HKO & 8.23 & 8.30 & 8.13 & 8.23 \\
17 & AGS & 8.18 & 8.27 & 8.21 & 8.27 \\
\hline
\end{tabular}

Tabel 3. Hasil pre test dan post test

No Nama

Pre test Post test

Hasil terbaik Hasil terbaik

(1)

(2)

(3)

(4)

1

AA

8.3

8.9

2

BR

8.5

9

3 FIR

8.4

8.8

4 MR

8.5

8.7

5

MDN

8.15

8.3

6 MKM

8.5

8.6

$7 \quad \mathrm{OE}$

8.4

8.8

8

HRN

8.7

9

9 SDI

8.7

8.85

10 HRI

8.5

8.7

11 LE

8.5

8.73

12 DD

8.6

8.67

13 MK

8.15

8.27

14 AHY

8.25

8.32

15

RMI

8.17

8.26

16

HKO

8.11

8.23 


\begin{tabular}{llll}
\hline 17 & AGS & 8.17 & 8.27 \\
\hline
\end{tabular}

Setelah semua data terkumpul langkah selanjutnya adalah melakukan analisis data penelitian, dalam penelitian ini menggunakan analisis statistik.

Tabel 4. Kerja untuk mencari Nilai " $t$ "

\begin{tabular}{|c|c|c|c|c|c|}
\hline \multirow[t]{2}{*}{ No } & \multirow{2}{*}{$\begin{array}{l}\text { Nomor } \\
\text { Subjek }\end{array}$} & \multicolumn{2}{|c|}{ Prestasi } & \multirow{2}{*}{$\begin{array}{l}\text { Gain (d) } \\
=X_{2}-X_{1}\end{array}$} & \multirow[t]{2}{*}{$\mathrm{X}^{2} \mathrm{~d}$} \\
\hline & & Pre-test $\left(\mathrm{X}_{1}\right)$ & Post-test $\left(\mathrm{X}_{2}\right)$ & & \\
\hline 1 & 2 & 3 & 4 & 5 & 6 \\
\hline 1 & 1 & 8.3 & 8.9 & 0.6 & 0.36 \\
\hline 2 & 2 & 8.5 & 9 & 0.5 & 0.25 \\
\hline 3 & 3 & 8.4 & 8.8 & 0.4 & 0.16 \\
\hline 4 & 4 & 8.5 & 8.7 & 0.2 & 0.04 \\
\hline 5 & 5 & 8.15 & 8.3 & 0.15 & 0.0225 \\
\hline 6 & 6 & 8.5 & 8.6 & 0.1 & 0.01 \\
\hline 7 & 7 & 8.4 & 8.8 & 0.4 & 0.16 \\
\hline 8 & 8 & 8.7 & 9 & 0.3 & 0.09 \\
\hline 9 & 9 & 8.7 & 8.85 & 0.15 & 0.0225 \\
\hline 10 & 10 & 8.5 & 8.7 & 0.2 & 0.04 \\
\hline 11 & 11 & 8.5 & 8.73 & 0.23 & 0.0529 \\
\hline 12 & 12 & 8.6 & 8.67 & 0.07 & 0.0049 \\
\hline 13 & 13 & 8.15 & 8.27 & 0.12 & 0.0144 \\
\hline 14 & 14 & 8.25 & 8.32 & 0.07 & 0.0049 \\
\hline 15 & 15 & 8.17 & 8.26 & 0.09 & 0.0081 \\
\hline 16 & 16 & 8.11 & 8.23 & 0.12 & 0.0144 \\
\hline 17 & 17 & 8.17 & 8.27 & 0.10 & 0.01 \\
\hline \multicolumn{2}{|c|}{ Jumlah } & $\sum 142.6$ & $\sum 146.4$ & $\sum 3.61$ & $\sum 1.3546$ \\
\hline & M & 8.388 & 8.611 & 0.212 & 0.079 \\
\hline
\end{tabular}

Pada langkah ini data yang sudah tercantum dalam table, Kemudian dimasukkan ke rumus " $t$-test" sebagai berikut, dimana:

$$
\begin{aligned}
& t=\frac{M d}{\sqrt{\frac{\sum x^{2} d}{N(N-1)}}} \\
& t=\frac{0.212}{\sqrt{\frac{0.5881}{17(17-1)}}} \\
& t=\frac{0.212}{\sqrt{\frac{0.5881}{272}}} \\
& t=\frac{0.212}{\sqrt{0.00216}}
\end{aligned}
$$




$$
\begin{aligned}
& t=\frac{0.212}{0,046} \\
& t=4,608
\end{aligned}
$$

\section{○ Menguji Nilai “ $t$ "}

Setelah mendapatkan nilai $t_{\text {hitung }}\left(\mathrm{t}_{0}\right)$ diperoleh nilai sebesar 4,608 Kemudian nilai $\mathrm{t}_{\text {tabel }}(\mathrm{tt})$ dengan derajat kebebasan (df) $\mathrm{N}-1=16$. Untuk dapat menolak Hipotesis Nihil $\left(\mathrm{H}_{0}\right)$ diperlukan nilai $\mathrm{t}_{\text {hitung }}$ sama atau lebih besar dari nilai $\mathrm{t}_{\text {tabel }}$ dan pada taraf signifikan 5\% menunjukkan angka sebesar hal ini berarti bahwa 4,608>2,120 atau dengan kata lain nilai $t_{\text {hitung }}$ yang diperoleh lebih besar dari angka batas penolakan Hipotesis Nihil $\left(\mathrm{H}_{0}\right)$ yang tercantum dalam tabel t. Untuk dapat menolak Hipotesis Nihil $\left(\mathrm{H}_{0}\right)$ diperlukan nilai $\mathrm{t}_{\text {hitung }}$ sama atau lebih besar dari nilai $\mathrm{t}_{\text {tabel. }}$. Dengan hasil analisis data yang signifikan, maka dengan dasar ini Hipotesis Nihil $\left(\mathrm{H}_{0}\right)$ ditolak dan Hipotesis Alternatif $(\mathrm{Ha})$ diterima. Berdasarkan kenyataan di atas yaitu nilai $t_{\text {hitung }}$ lebih besar dari $t_{\text {tabel. }}$. Maka dengan demikian nilai " $t$ " yang diperoleh dalam penelitian adalah "signifikan".

Pembahasan

Berdasarkan pada analisa data untuk menjawab hipotesis penelitian yang diajukan, diperoleh nilai " $\mathrm{t}$ " hitung sebesar 4,608 maka berdasarkan taraf signifikan 5\% dan df $\mathrm{N}-1$ $(17-1)=16$, ternyata batas penolakan hipotesisnya nol yang dinyatakan dalam tabel adalah 2,120 . Kenyataan ini menunjukan bahwa t hitung yang diperoleh dari hasil analisis data sebesar 4,608 berada diatas angka batas penolakan hipotesis nol yang besarnya 2,120. Penelitian ini menunjukan bahwa analisis data terdapat perbedaan yang nyata, sehingga disimpulkan bahwa ada pengaruh latihan plyometrik (pullover toss) terhadap hasil lemparan kedalam (throw in) dalam permainan sepak bola pada klub Pelor Mas sekotong tahun 2014. Menemukan bahwa terdapat pengaruh yang positi kekuatan otot lengan terhadap jauhnya lemparan kedalam pada subyek penelitian, ini merupakan informasi penting dan sangat berharga bagi para guru pendidikan jasmani dan olahraga serta pelatih dan Pembina dalam melakukan pembinaan terhadap pemain sepak bola.

\section{Simpulan}

Berdasarkan hasil analisis data terdapat perbedaan yang nyata, sehingga disimpulkan bahwa ada pengaruh latihan plyometrik (pullover toss) terhadap hasil lemparan kedalam (throw in) dalam permainan sepak bola pada klub Pelor Mas sekotong. Peneliti menemukan bahwa terdapat pengaruh yang positif dikekuatan otot lengan terhadap jauhnya lemparan kedalam pada subyek. Ini merupakan informasi penting dan sangat berharga bagi para guru pendidikan jasmani dan olahraga, serta pelatih dan Pembina dalam melakukan pembinaan terhadap pemain sepak bola, Agar dapat dijadikan pedoman untuk lemparan ke dalam yang benar dan efektif dapat menjadi serangan yang berbahaya.

\section{Daftar Pustaka}

Arikunto, S. 2010. Prosedur Penelitian Suatu Pendekatan Praktik. Jakarta: PT Rineka Cipta. Abdul Haqqiadnan. (2013). Pengaruh Latihan Passing Berpasangan Terhadap Ketepatan Passing Pada Permain Sepakbola SSB Petrogres Gresik. Skripsi. Surabaya: FKIP ADIBUANA SURABAYA. 
Annas, B., Dinata, K., \& Daniyantara, D. (2018). Hubungan Imt Dengan Kelincahan Menggiring Bola Pada Siswa Putera Ekstrakulikuler Sepak Bola Siswa Sman 1 Aikmel Tahun 2017. Jurnal Porkes, 1(1), 07-13.

Ambarukmi,D.A.Dkk. 2007 Pelatihan Pelatih Fisik Level I, Deputi Bidang Peningkatan Prestasi dan IPTEK Olahraga. Kemenpora

Arikunto Suharsimi, 2006. Prosedur Penelitian . Jakarta: PT Rineka

Bompa, T., \& Buzzichelli, C. (2015). Periodization training for sports, 3e. Human kinetics

Batty. Eric C. (2012). Latihan Metode Baru Sepak Bola Serangan. Bandung: CV Pionir Jaya Bandung

Chandra, S. 2010. Pendidikan Jasmani Olahraga dan Kesehatan. Jakarta: PT Arya Duta Lembaga Penelitian dan Pendidikan (LPP) Mandala.

Chu, Donald A. 2000. Latihan Tenis Tenaga. Jakarta : PT Raya Grafindo Persada

Daniyantara, D., Suryadi, L. E., \& Nuhayadi, S. A. (2020). Perbandingan Tingkat Keterampilan Dribbling Dengan Metode Latihan Slalom Dribbling Dan Tepukan Dribbling. Jurnal Porkes, 3(1), 49-52.

Djoko Pekik Irianto. (2002). Dasar Pelatihan. Yogyakarta: FIK UNY

Hulfian, L. (2020). Latihan Kelincahan Boomerang Run Dapat Meningkatkan Keterampilan Menggiring Bola Dalam Permainan Futsal. Jurnal Porkes, 3(1), 9-14.

Jovanovic, M., Sporis, G., Omrcen, D., \& Fiorentini, F. (2011). Effects of speed, agility, quickness training method on power performance in elite soccer players. The Journal of Strength \& Conditioning Research, 25(5), 1285-1292.

Jusran, S., \& Hariadi, H. (2020). Kontribusi Kecepatan, Kelincahan Dan Keseimbangan Dengan Kemampuan Menggirng Dalam Permainan Futsal. Jurnal Porkes, 3(1), 3743.

Kemendikbud. 2013. Pendidikan Jasmani, Olahraga, dan Kesehatan. Jakarta: Politeknik Negeri Media Kreatif Jakarta

Lhaksana, J. (2011). Taktik \& Strategi futsal modern. Be Champion

Luxbacher, Joseph. (2011). Sepakbola Edisi Dua. Rajagrafindo Persada.

Maksum, Ali. 2009. Metodologi Penelitian Dalam Olahraga. Surabaya: Fakultas Ilmu Keolahragaan-Universitas Negeri Surabaya.

Mielke, D. (2007). Dasar-Dasar Sepak Bola. Bandung: Pakar Raya.

Muluk, Sukadiyanto. 2011. Pengantar Teori dan metodologi Melatih Fisik. Bandung: Lubuk Agung. Semarang

Maksum, A. (2012). Metode Penelitian Dalam Olahraga. Surabaya. Unesa University Press

Muhammad. (2012). Pengaruh Latihan Passing Satu Dua Sentuhan Terhadap Kemampuan Passing Di Sekolah Sepakbola Kelud Putra Sukodono Sidoarjo.Surabaya: FKIP ADIBUANA SURABAYA.

Mardhika, R. (2020). Standing Jump Over Barrier Mempengaruhi Keterampilan Menendang Bola (Shooting) Cabang Olahraga Sepakbola. Jurnal Porkes, 2(2), 50-57.

Quddus, A., Dinata, K., \& Daniyantara, D. (2018). Pengaruh Variasi Latihan Terhadap Peningkatan Keterampilan Bermain Sepak Bola Pada Club Putra Baja Fc Tahun 2017. Jurnal Porkes, 1(1), 21-26.

Sugiyono. 2010. Metode Penelitian Kuantitatif Kualitatif dan R\&D. Bandung: Alfabeta.

Sporiš, G., Milanović, Z., Trajković, N., \& Joksimović, A. (2011). Correlation between speed, agility and quickness (SAQ) in elite young soccer players. Acta Kinesiologica, 5(2), 36-41.

Sugiyono. 2010. Statistika Untuk Penelitian. Bandung : Alfabeta.

Sugiyono. 2011 Metode Penelitian Pendidikan (Pendekatan kualitatif, kuantitatif, dan $R \& D$. Bandung :Alfabeta.

Suharjana. 2007. Latihan Beban. Yogyakarta : FIK UNY. 
Sukadiyanto. 2005. Pengantar Teori dan Melatih Fisik. Yogyakarta: FIK UNY.

Saputra, S. Y., \& Suarti, N. K. A. (2019). Pengaruh Gaya Mengajar Resiprokal Terhadap Hasil Menendang Bola Dalam Permainan Sepak Bola pada Siswa Putra Kelas VII SMPN 1 Gerung Lombok Barat. Jurnal Porkes, 2(1), 06-12.

Tim PSSI. 2010. Laws Of The Game. Jakarta: PSSI

Wora, D., Adiatmika, I P., Fufu, O., Adiputra, N., Muliarta, M., \& Adiarta, P. G. (2017). Pelatihan Zig-Zag Run Lebih Efektif Meningkatkan Kelincahan Menggiring Bola Dari Pada Pelatihan Shutlle Run Dalam Permainan Futsal.

Yulifri. 2011. Permainan Sepak Bola. Padang: Fakultas Ilmu Keolahragaan Universitas Negeri Padang 